\title{
Deconstructing automobile messaging: Clues to brand strategy
}

Received (in revised form) 28th January, 2003

\section{Howard Moskowitz}

is president and chief executive of Moskowitz Jacobs Inc., a firm he founded in 1981. He is an experimental psychologist in the field of psychophysics and an inventor of market research technology.

\section{Barbara Itty}

joined Moskowitz Jacobs (MJI) in 2000 as an international coordinator and soon after became a brand coordinator for i-novation Inc., the web-based sister company of MJI.

\section{Carly Fink}

graduated with honours from Lafayette College in 2001 and was awarded the Fredrick Knecht Detwiller prize for excellence in fine art and art history. Currently she is working towards her masters in advertising and applied research at Boston University College of Communications.

\section{Jeffrey Ewald}

is President of the Optimization Group, Inc., Michigan. He learned classical marketing at General Mills, Campbell Soup and J. Walter Thompson. At Optimization Group, Jeff applies measurement and continuous improvement priniciples to help clients improve the effectiveness of their marketing expenditures.

Abstract This paper looks at the messages conveyed by six different automobile models in order to identify the type of strategy adopted by the manufacturer of each model. A sampling of current messages yielded 150 different elements, edited into short declarative statements. These elements were combined into new combinations and the combinations were rated on interest. Conjoint analysis showed the relative importance of different elements as acceptance drivers, with none standing out as having strong acceptance drivers. Four segments emerged, with each model appealing to the segments, but to different degrees. Deconstruction helps one to understand and dissect the brand strategy by a quantitative analysis of its messaging.

\section{INTRODUCTION}

\section{Messaging as a key to understanding the brand}

In today's world the consumer is awash with advertising and promotion designed

Howard Moskowitz Moskowitz Jacobs Inc, 1025 Westchester Avenue White Plains, NY 1064, USA.

Tel: +19144217400 e-mail: mjihrm@sprynet.com to generate both immediate purchase and to create a favourable positioning for the longer term. Delivery on performance is vital, but positioning is critical as well. Positioning is the predisposition to purchase a product or service, based upon what one thinks and feels about it. Positioning can be used both for tactics and for long-term competitive advantage against direct and indirect competitors. ${ }^{1}$

One key approach analyses what is already known about a product or service in order to create a profile for optimum positioning. The conventional research exercise profiles one or several products on a large array of characteristics to create a product 'signature'. The signature is presumed to 
be somehow isomorphic with the position in the mind. To the degree that the consumer can accurately profile two products and to the degree that these products differ on key attributes, the marketer gets a prima facie sense of knowing how these products truly differ from each other. The market researcher merely needs to create the proper research instrument (a long checklist or profile questionnaire), validate the questionnaire and then proceed with the research. Everything else becomes statistical analysis and summarisation.

An alternative way of understanding the positioning of a brand through its messages uses the research procedure known as conjoint analysis. This method reduces systematically designed stimuli by means of regression analysis.

Experimental design generates combinations of features. The researcher presents these new ideas to consumers, who then react to these as concepts, much as they would react to conventional concepts. ${ }^{2}$ The researcher then discovers what elements drive strong positive responses versus strong negative responses. Conjoint measurement, or tradeoff analysis, thus becomes a strong development tool. It has primarily been used with limited numbers of elements, because of the need to test various combinations. ${ }^{3}$ More recent applications of conjoint analysis, however, have expanded its scope to hundreds of elements opening up new vistas of application. ${ }^{4}$

Conjoint measurement has found an additional use, namely in the analysis of current messages. Since conjoint analysis provides a measure of utility for the different messages, one can use it as a retrospective, rather than as a prospective, tool. Rather than looking at the promise of different messages for future products and services, one can look at the impact or efficacy of current messages.
Respondents do not necessarily know that the stimuli to which they are exposed comprise already-existing messages. Rather, they simply are presented with a set of stimuli and instructed to respond. Thus, it becomes possible to interweave current and new messages in a format resembling conventional advertising and concept testing and, where appropriate, to measure the impact of a wide variety of existing messages. Furthermore, advances in conjoint analysis make it even more feasible to test a wide variety of different messages. Whereas studies limited to ten to 20 elements may not be particularly interesting, because such a range cannot hope to cover the array of messages, studies of 100-300 elements become more interesting and instructive. The marketer and researcher can deconstruct a fuller array of competitor messages.

\section{Deconstructing messaging}

The sequence of deconstruction and stimulus preparation is fairly straightforward, as outlined in Table 1, based upon approaches previously developed. ${ }^{5}$ Deconstruction works with phrases as raw material obtained from the competitive frame, but without brand names. All of the communications for a car model are fair game as inputs because they represent what could be said. It is important to deconstruct elements from mutually substitutable car models, making the elements created consistent with each other.

\section{Segmenting consumers and the problem of direct applicability}

The principle of segmentation is widely used by marketers, and forms much of the strategy in the automotive industry. Demographics for marketing research help to define, identify and segment a 
Table 1: Strategy for deconstruction studies

Gather 'in-market' ads as raw material. Focus on mutually substitutable car models, so that the raw material is fairly homogeneous.

Deconstruct ads to elements. Where possible make these elements into standalone, declarative phrases.

Cull the set of elements to reduce obvious redundancies. If the deconstruction study is to be run on the internet, then cull the elements to a total of 150 or fewer. If the deconstruction study is to be run on a PC, with a personal interview (computer aided personal interview), then cull the full set of elements to no more than 300 .

Classify the elements into categories. A category comprises a set of related elements. The classification approach is simply a bookkeeping device that ensures that a single concept will comprise no more than one element from a category. In this way it becomes possible to have a single category comprise a variety of different ideas. Since there is only one element per category in any concept, there is no chance that two mutually contradictory ideas from the same category could ever appear.

Dimensionalise the elements by locating each element on a set of four to eight non-evaluative semantic scales (eg, for males versus for females). Dimensionalisation will be used for data imputation of missing utility values in the conjoint task, for concept-response segmentation and for the creation of new automobile concepts.

Restrict pairs of elements from appearing, if they comprise contradictory elements.

Mix/match and test combinations of elements. Use experimental design to create these combinations. If possible use a single design structure, but have the actual elements fleshing out that design structure differently from one respondent to another. In that way, ensure that there will be no repeat concepts, and therefore the probability of bias will be reduced substantially.

Invite respondents to participate on an internet-based interview.

Estimate part-worth element utilities and impacts, using dummy-variable regression analysis.

Segment customers on the basis of impact patterns to create new subgroups.

Optimise new concepts embodying product and/or positioning.

customer base. Lifestyle segmentation with demographic mapping helps to identify potential customers. Lifestyle segmentation uses demographic and aggregated consumer demand data to classify consumers into market segments. These segments share similar interests, purchasing behaviour, financial behaviour and demand for specific services. ${ }^{6}$ What has been problematic, however, is the nature of the segmentation. Originally, segmentation was done on the basis of geodemographic variables, but it eventually became rather obvious that individuals in the same geodemographic class did not necessarily share the same mind set. As a consequence, marketers turned to segmentation on the basis of psychological factors. ${ }^{7}$ Studies have been created to evaluate attitude measurement by three criteria: the measurement instrument used, the type of behaviour criteria studied and the situation in which the behaviour occurred. ${ }^{8}$

One could create different segments based upon the patterns of responses to a variety of questions in a large survey. Indeed, this type of segmentation led to overarching segmentation systems, encompassing lifestyles. ${ }^{9}$ This segmentation groups people who have similar behaviour and characteristics, which could be advantageous in identifying a specific population in a target market. Through the segmentation, those specific factors that group together variables with the same common source of variation can be identified. ${ }^{10}$ The overarching segments, in turn, are attractive from a popular point of view. 
Segments have publicity value as well as strategic value. They are good for 'sound bites'. Segments make interesting stories for popular magazines, and can change the way people think about the product and service categories. What is difficult, however, is the mapping of general category membership to the specific action that one should take with a particular brand. For cars, knowing that a person seeks modern technology does not particularly identify what features and messaging would work for that segment. Would every statement about technology work? It is relatively easy to eliminate certain obvious incompatibilities, such as emotional talk to an individual falling into the rational, fact-oriented, technology-sensitive segment. But, what specific message does the individual need to hear to create a positive response? Beyond the segmentation it is often still 'hit or miss', albeit played out in a narrower framework.

For deconstruction work it is important to be able to apply segmentation principles to the large number of stimulus inputs. ${ }^{11}$ The method of IdeaMap, used here, also enables the researcher and the marketer to use this wide array of stimuli as inputs to the segmentation. Rather than limiting the focus to the 20-40 elements and thus having a segmentation that is based upon a limited range of input, the IdeaMap-based segmentation works with a larger set of $100+$ elements.

Furthermore, rather than segmenting on the basis of the magnitude of utility values alone, the segmentation approach used here is based on an organising principle first used in psychophysics (a branch of experimental psychology) and in product research. The principle states that as a sensory attribute increases, liking first increases, peaks and then drops down. Each individual respondent generates a profile of optimal sensory levels for a product. Individuals showing similar optimum sensory levels fall into the same cluster or segment. The approach was shown to yield very powerful segmentations with radically different products appealing to the different segments, ${ }^{12,13}$ and was used to create products as different as coffee, credit cards and orange juice. On a practical level, products such as Vlasic Zesty pickle and the line of Vlasic pickles, as well as Tropicana Grovestand Orange Juice, were created according to this organising principle.

The segmentation method can be extended to conjoint analysis results rather straightforwardly. The element utilities replace the product liking scores. The locations on the non-evaluative semantic scales replace the product sensory characteristics. The same approach, that is, identifying the optimum level where a person's liking peaked, can be done for the concept elements, only this time the optimum is the maximum utility score. Rather than finding the sensory level corresponding to this maximum liking, the semantic differential value corresponding to the maximum utility is then identified. The results generate a profile of semantic levels corresponding to optimum utility values. This profile is generated on an individual-by-individual basis.

Applying this approach to concept elements generates different groups of respondents, showing different locations on the semantic differential scales where their utilities maximise. Rather than clustering individuals on the basis of the size of their utility values (which is scale dependent and, thus, possibly subject to artifacts), the approach clusters individuals on profiles in the semantic profile domain. Individuals falling into different segments show different peaks of 'meaning' where their utilities maximise. This segmentation has been done for concepts about products such as coffee 
Table 2: Example of elements, including category, model from which the element was sourced and the text of the element (where necessary the text was slightly altered to create a simple declarative statement)

\begin{tabular}{|c|c|c|}
\hline Category & Model & Text \\
\hline Exterior & Ford Contour & Comes with fog lamps \\
\hline Exterior & Mazda 626 & $\begin{array}{l}\text { Free-surface reflector halogen headlights with automatic shut-off } \\
\text { feature }\end{array}$ \\
\hline Exterior & Oldsmobile Alero & $\begin{array}{l}\text { Four-wheel independent suspension - each wheel responds } \\
\text { independently to uneven road surfaces providing a smoother, } \\
\text { more controlled ride }\end{array}$ \\
\hline Interior & Chevrolet Malibu & Available with rear seat heat ducts \\
\hline Interior & Ford Contour & Rear seat compartment heat ducts \\
\hline Interior & Saturn LS & Rear seatbacks can be folded to expand cargo \\
\hline Performance & Chevrolet Malibu & Front independent strut suspension with anti-roll bar \\
\hline Performance & Ford Contour & A $2.5 \mathrm{~L}$ six-cylinder engine w/four-speed automatic transaxle \\
\hline Performance & Honda Civic & New double-wishbone suspension system \\
\hline Safety & Ford Contour & SecuriLock $^{\mathrm{TM}}$ passive anti-theft system \\
\hline Safety & Saturn L100 & $\begin{array}{l}\text { With energy-absorbing knee bolsters for driver and front } \\
\text { passenger }\end{array}$ \\
\hline Safety & Saturn L100 & Built with safety tempered side and rear window glass \\
\hline Taglines & Mazda 626 & Beautiful and versatile \\
\hline Taglines & Mazda 626 & Safety is a high priority \\
\hline Taglines & Oldsmobile Alero & V-6 $200 \mathrm{lb}-\mathrm{ft}$ of torque generates good getaway \\
\hline Taglines & Oldsmobile Alero & Powerful all-disc braking system includes standard ABS \\
\hline
\end{tabular}

and credit cards. ${ }^{14}$ In deconstruction work the segmentation has been applied to functional foods ${ }^{15}$ and energy. This paper presents the deconstruction method coupled with segmentation as a way to create new sub-groups for automobile communication.

What is important about the above-mentioned segmentation, combined with conjoint analysis, is its immediate applicability to the problem at hand. The segmentation does not claim to be general. However, if across studies with different products and services one discovers the same segments repeating, then this commonality across categories suggests a likely general segmentation transcending any particular study.

\section{METHOD}

\section{Stimuli}

The elements for this study were created using the current in-market messaging from six models (Ford Contour, Mazda 626, Oldsmobile Alero, Chevrolet
Malibu, Saturn L100 and Honda Civic). These models are, in general, reasonably similar and at the same time provide a substantial amount of printed information from which the elements can be extracted. Examples of the raw material appear in Table 2. The table shows the category into which the element was placed, the model and the actual text.

\section{Dimensionalisation}

From the authors' experience, a respondent can only assess a limited number of concept elements, usually 20-40, embedded in approximately 60 concepts. Beyond that number the respondent must be paid to participate, but even so a typical respondent can only assess about 100 concepts before complaining of fatigue. That limited number is adequate if the goal of the research is to identify the features of a new product. Through pre-work, one can narrow down the number of possible elements to the restricted limit of 20-40. For deconstruction analysis, however, the 
Table 3: Location of elements on six semantic differential scales

\begin{tabular}{|c|c|c|c|c|c|c|}
\hline $\begin{array}{l}\text { Anchor point } \mathbf{1}= \\
\text { Anchor point } 9=\end{array}$ & $\begin{array}{l}\text { Affordable } \\
\text { vs } \\
\text { Premium }\end{array}$ & $\begin{array}{l}\text { Single } \\
\text { vs } \\
\text { Family }\end{array}$ & $\begin{array}{l}\text { Functional } \\
\text { vs } \\
\text { Luxurious }\end{array}$ & $\begin{array}{l}\text { Comfort } \\
\text { vs } \\
\text { Performance }\end{array}$ & $\begin{array}{l}\text { Ordinary } \\
\text { vs } \\
\text { Unique }\end{array}$ & $\begin{array}{l}\text { Traditional } \\
\text { vs } \\
\text { New }\end{array}$ \\
\hline \multicolumn{7}{|l|}{ Concept element } \\
\hline Comes with fog lamps & 6.1 & 5.4 & 6.0 & 4.6 & 4.9 & 4.5 \\
\hline $\begin{array}{l}\text { Free-surface reflector halogen headlights with } \\
\text { automatic shut-off feature }\end{array}$ & 6.1 & 5.3 & 4.9 & 4.6 & 5.8 & 5.4 \\
\hline Available with rear-seat heat ducts & 6.1 & 5.9 & 5.5 & 3.3 & 5.5 & 5.6 \\
\hline Rear seat compartment heat ducts & 6.4 & 6.1 & 5.3 & 2.3 & 4.9 & 5.9 \\
\hline Rear seatbacks can be folded to expand cargo & 4.5 & 5.8 & 4.3 & 4.3 & 4.5 & 4.6 \\
\hline $\begin{array}{l}\text { Front independent strut suspension with } \\
\text { anti-roll bar }\end{array}$ & 5.9 & 4.8 & 5.3 & 7.3 & 4.6 & 4.8 \\
\hline $\begin{array}{l}\text { A } 2.5 \mathrm{~L} \text { six-cylinder engine } w / \text { four-speed } \\
\text { automatic transaxle }\end{array}$ & 5.6 & 4.9 & 5.3 & 6.3 & 4.8 & 4.1 \\
\hline New double-wishbone suspension system & 5.5 & 4.5 & 6.4 & 7.1 & 5.6 & 7.3 \\
\hline SecuriLock $^{\mathrm{TM}}$ passive anti-theft system & 5.8 & 5.3 & 4.6 & 3.3 & 6.1 & 5.8 \\
\hline $\begin{array}{l}\text { With energy-absorbing knee bolsters for driver } \\
\text { and front passenger }\end{array}$ & 7.0 & 5.9 & 5.1 & 5.3 & 5.8 & 7.4 \\
\hline $\begin{array}{l}\text { Built with safety tempered side and rear } \\
\text { window glass }\end{array}$ & 5.4 & 5.6 & 4.8 & 5.0 & 5.6 & 6.6 \\
\hline Beautiful and versatile & 4.1 & 5.0 & 6.8 & 5.1 & 4.6 & 5.0 \\
\hline Safety is a high priority & 4.8 & 4.8 & 4.3 & 5.5 & 4.9 & 5.1 \\
\hline $\mathrm{V}-6200 \mathrm{lb}-\mathrm{ft}$ of torque generates good getaway & 5.1 & 3.5 & 6.0 & 7.5 & 6.3 & 5.6 \\
\hline $\begin{array}{l}\text { Powerful all-disc braking system includes } \\
\text { standard ABS }\end{array}$ & 4.8 & 5.6 & 4.5 & 6.6 & 5.0 & 5.3 \\
\hline
\end{tabular}

goal is to increase the scope of the study by assessing many elements, not to limit the number of elements to a reduced, manageable number.

The dimensionalisation procedure was presented by Moskowitz and Martin ${ }^{16}$ as one way to deal with the need to create a utility function or impact function for every element, for every respondent. Dimensionalisation refers to the location of the elements by respondents on a set of non-evaluative semantic scales. By locating the elements on a set of dimensions, the researcher can use the information from a single respondent's data in order to estimate how that respondent would have evaluated all of the elements not tested. The algorithm works by replacing untested elements with the average of their neighbours. The algorithm repeats this replacement process for untested elements only, until there is no material change in the replacement value. The algorithm allows the respondent to assess a limited number of elements in combination, within the context of a short interview. In the background the computer fills in missing values. The process is efficient, and produces a complete utility set for each respondent, even though the respondent tested only a fraction of the elements. Table 3 presents an example of the dimensionalisation, showing the location of various elements on these dimensions.

\section{Internet interview}

The internet interview was conducted among members of a loyalty programme, who received points for participating in surveys. There were approximately 250,000 members of this particular loyalty programme (freeride.com) when the survey was done (October, 2000). Prior to the actual study the participants had completed a general interest survey, which included automobile purchase and use patterns. Only members of the panel who defined themselves as interested in 
Table 4: Profile of the respondents from key sub-groups and additive constant from the utility model

\begin{tabular}{|c|c|c|c|c|c|}
\hline & Base & $\begin{array}{l}\text { Additive } \\
\text { constant }\end{array}$ & & Base & $\begin{array}{l}\text { Additive } \\
\text { constant }\end{array}$ \\
\hline Total panel & 349 & 37 & Price $20 \mathrm{~K}$ or less & 168 & 38 \\
\hline Males & 169 & 35 & Price $21 \mathrm{~K}$ or more & 181 & 37 \\
\hline Females & 180 & 40 & Get information from ads & 219 & 39 \\
\hline Age $21-35$ & 195 & 35 & Get information from web & 235 & 34 \\
\hline Age $36-65$ & 154 & 41 & Get information from recommendations & 168 & 34 \\
\hline Income $50 \mathrm{~K}$ or less & 164 & 41 & Get information from auto shows & 117 & 39 \\
\hline Income $50 \mathrm{~K}$ or more & 185 & 34 & Mindset - utilitarian & 168 & 33 \\
\hline Current vehicle - sedan & 143 & 42 & Mindset - enthusiast & 148 & 44 \\
\hline Current vehicle - SUV or van & 105 & 30 & Mindset - not a shopper & 147 & 33 \\
\hline Buy - Next 12 months & 153 & 39 & Segment $4 \mathrm{~A}$ & 87 & 53 \\
\hline Buy - One year or later & 154 & 35 & Segment 4B & 58 & 59 \\
\hline Plan to buy sedan & 124 & 44 & Segment $4 \mathrm{C}$ & 100 & 26 \\
\hline Plan to buy SUV or van & 189 & 36 & Segment 4D & 104 & 23 \\
\hline
\end{tabular}

surveys on cars were selected.

Furthermore, respondents were selected on the basis of the type of car that they currently possessed and whether they were interested in buying a car in the next six months.

Invitations totalling 4,000 were sent out to these members, giving them a link. From the invitees, 349 respondents completed the interview. The interview comprised an orientation page, a 60-concept conjoint study and a 15-question classification study. Each concept comprised between two and four concept elements. Each respondent tested concepts developed by an experimental design unique to that individual. Therefore, the data set for analysis comprised utility values for each element for each of the 349 respondents and significant amounts of background information obtained from the study itself and from additional information previously gathered about the respondent (see Table 4).

\section{Respondents}

One of the ongoing issues in automobile and other research is who is the true representative of the population. Although there are stringent criteria adopted by automobile manufacturers for their research into new products and into tracking studies, such stringent criteria need not be applied for a first deconstruction study. The goal here is to find automobile users, look at their individual utility functions, divide the respondents by their classification scores, and then see how closely the sub-groups agree with each other in their response to the current positioning. Afterwards, it makes sense to apply the most expensive criteria so commonly used in the industry for screening and qualifying respondents.

The description of the 349 respondents appears in Table 4 . The panel was reasonably balanced, recognising, however, that the respondents were self-selecting. What is important, however, is that the information provides a good sense about the income, gender and age distribution, as well as their interest in buying a car and how they get information. As will be shown in the results section, this information about the respondents was not sufficient to create truly different groups with divergent mind-sets.

\section{Modelling by dummy variable regression analysis}

Modelling creates a simple additive equation of the form: Utility 
$=\mathrm{k}_{0}+\mathrm{k} 1$ (Element \#1) $+\mathrm{k}_{2}$ (Element \#2) ... $\mathrm{k}_{36}$ (Element \#36). Each

respondent evaluated 60 different combinations comprising 36 elements, systematically varied in concepts, with every concept comprising two to four elements. Since the elements were combined according to an experimental design it is straightforward to do a regression analysis on the ratings. Two regression analyses were run for the data for each respondent. The first analysis related the presence/absence of the concept elements to the nine-point rating assigned by the respondent. The 'persuasion' model was used to establish the goodness of fit of the model to the individual's data. The second analysis was done after the respondent's ratings were recoded so that ratings of one to six on the nine-point scale were recoded to zero, and ratings of seven to nine were recoded as 100 . This analysis is similar to the top two-box recoding of purchase interest scales. The recoding changes the data from a measure of intensity of concept acceptance to membership of an acceptor group. Other cutoff levels could be used (eg, eight to nine on the nine-point scale), but the senior author's experience has been that this type of recoding works quite well and yields similar findings to recoding of only eight to nine. Since a respondent only evaluated 36 of the 150 concept elements, it was necessary to estimate the utility values of the remaining, untested elements by the data imputation mentioned above.

\section{RESULTS}

\section{Establishing data validity}

One recurrent question with conjoint measurement in particular and with internet-based research in general is the degree to which the data are valid.
Validity as a concept has many aspects, such as predictive validity (do the data predict future performance on other types of measures?), construct validity (do the interest data really measure degree of actual potential purchase?), or face validity (do the data appear to measure what they say they measure?). Validity is a thorny issue in research. One measure of validity, and certainly not the only one, is consistency, or the degree to which the respondent is consistent in the ratings that he assigns. Consistency can be assessed conveniently in experimentally-designed studies like conjoint measurement through the goodness-of-fit statistic. This is the Pearson multiple $\mathrm{R}^{2}$, which shows the percentage of variation in the ratings accounted for by the presence or absence of the concept elements. If the respondent is consistent then the $\mathrm{R}^{2}$ value should approach 1.0. If the respondent is inconsistent (guesses instead of answering truthfully) then the $\mathrm{R}^{2}$ value should approach zero. For 60 combinations (cases) comprising 36 elements (predictors) $\mathrm{R}^{2}$ values about 0.65 are highly significant. Figure 1 shows that a clear 18 per cent of the data can probably be discarded, and another 10 per cent of the data are at the lower end of statistical significance. Thus, approximately 65 per cent of the data are highly significant by tough statistical criteria $(p<0.05)$ and a full 82 per cent of the data show good relation between predicted and estimated ratings.

\section{Basic interest level as indicated by the additive constant}

The additive constant for the dummy variable regression $\left(\mathrm{k}_{0}\right.$ in the equation) shows the conditional probability of a respondent being interested in the car given a concept that in theory has no elements. Clearly, all concepts evaluated 


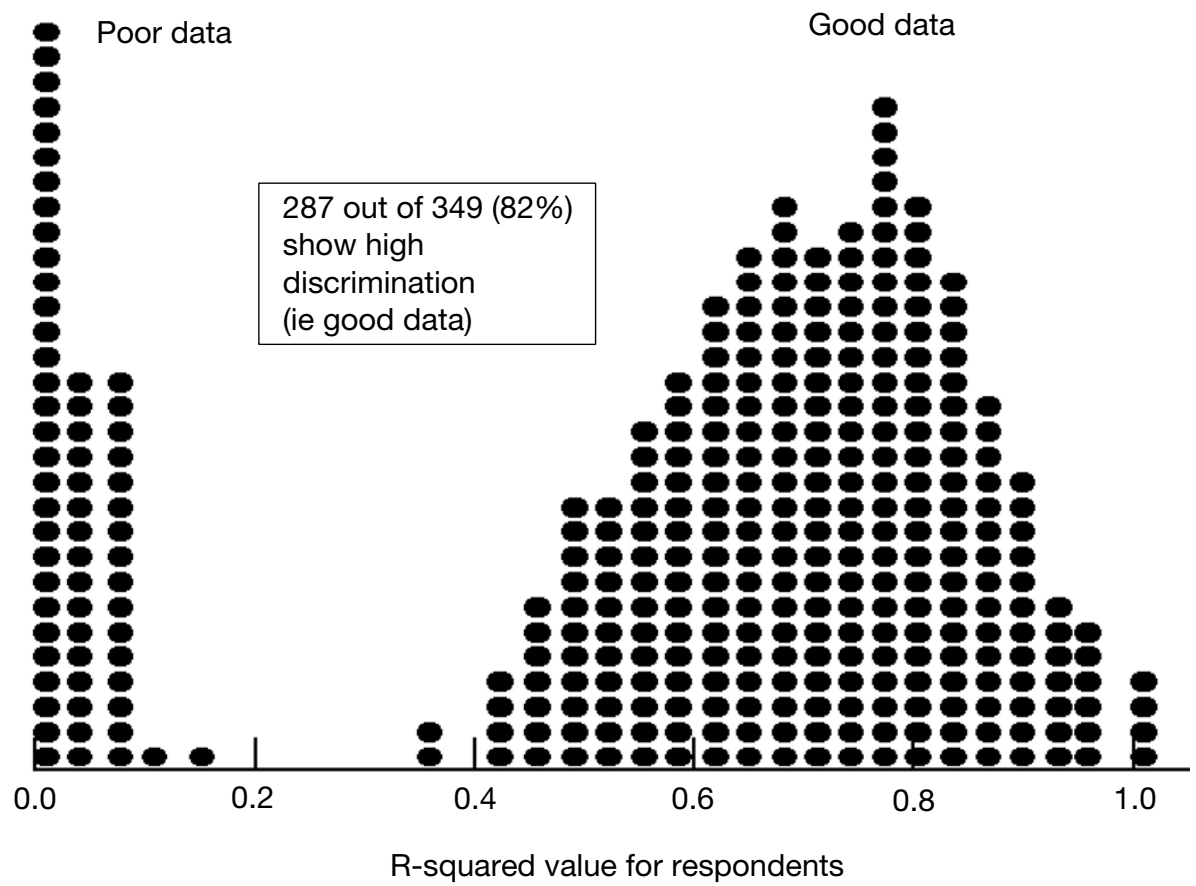

NB Good data are defined as a model that describes the results $\left(R^{2}>0.05\right)$ and highly significant results are those showing goodness of fit statistics with $R^{2}>0.65(p<0.05)$

Figure 1: Goodness of fit of the 349 individual utility functions

by any single respondent comprised some elements, so that the additive constant is a purely computed parameter in regression analysis. Nonetheless, the constant can be interpreted as the basic interest, and therefore as a baseline value. The additive model comes from the dummy variable regression in which the ratings on the nine-point interest scale were transformed to zero (not interested) or 100 (interested). Table 4 shows the values for a variety of groups. What emerges quite clearly is the similarity of these values for the different sub-groups. All constants lie around 35-45, suggesting a modest level of basic interest. There are some differences among sub-groups:

— females show higher constants than males

- older respondents show higher constants than younger respondents
- lower income respondents show higher constants than higher income people

- sedan owners show much higher constants than SUV owners

- respondents likely to buy in the next six months show higher constants than respondents likely to buy later

- price of car does not affect the constant

- those who find out about cars from auto shows or who are self-described auto enthusiasts show higher constants.

\section{Total panel - What wins? What loses? Who gets it right?}

The utility value of an element shows the additional conditional probability that a person will rate the concept as interesting (seven to nine) if the element is inserted into the concept. One can 
Table 5: Source, element and utility value for the top scoring elements for the total panel

\begin{tabular}{llc}
\hline Source & & Total \\
\hline \multicolumn{2}{l}{ Additive constant } & 37 \\
Olds & Rust and dent resistant steel body panels & 9 \\
Olds & Lock-out prevention feature - sounds a chime and disables the & 9 \\
& power locks if the ignition key remains in the ignition & 9 \\
Mazda & Traction control system & 8 \\
Ford & 15-inch eight-spoke aluminium wheels & 8 \\
Ford & An AM/FM stereo with single CD player and premium sound & 8 \\
Olds & Exhaust system made of stainless steel & \\
\hline
\end{tabular}

create concepts by beginning with the additive model, and then put in two to four elements to create the combination. The sum of the utilities and additive constant shows the estimated interest and conditional probability of the concept achieving a rating of seven to nine. Norms for the elements are as follows, based on over 1,000 of these studies in the commercial sector:

- utility $>16+$ extremely important element

- utility $>11-15$ very important element

- utility $>6-10$ significant and relevant

— utility $>0-5$ adds, but probably very little

— utility $<0$ subtracts from interest.

In the creation of winning concepts it is best to have a high score that results from a moderate additive constant, but very high-scoring, mutually consistent concept elements so that the elements do the work of persuading. A high constant with low elements might lead to the same result, but primarily because the basic interest is high to begin with and almost any execution will work so that the elements do not really contribute in this situation. A quick glance at the utility values plotted against the six different models shows no model to have elements that do very well or very poorly (Figure 2). Other deconstruction studies using current messaging also show narrow ranges for the utility values. None are negative, meaning that the process of screening the messages does an effective job of eliminating clearly poor messages, at least for the entire panel. On the other hand, this screening also eliminates elements that might have scored better than the highest value achieved (+9). Representative results appear in Table 5.

\section{Does self-description make a difference?}

One interesting way to divide the respondents is by self-stated interest in cars. Respondents described themselves by one of three categories: utilitarian, enthusiast or non-shopper. Table 6 shows virtually no major differences in the utility patterns. The differences are slightly quantitative (eg, whereas one segment might show a utility value of +10 for an element, another segment might show a utility value of +7 ). This similarity of self-description, only one of several such similar results found by segmenting through self-description, means that conventional ways to divide the population may be easy to do, but do not generate much new insight. The same type of high correlation among elements occurs for respondents seeking information about cars in different ways. For example, the correlation of utility values for those seeking information about cars through advertisements is, 


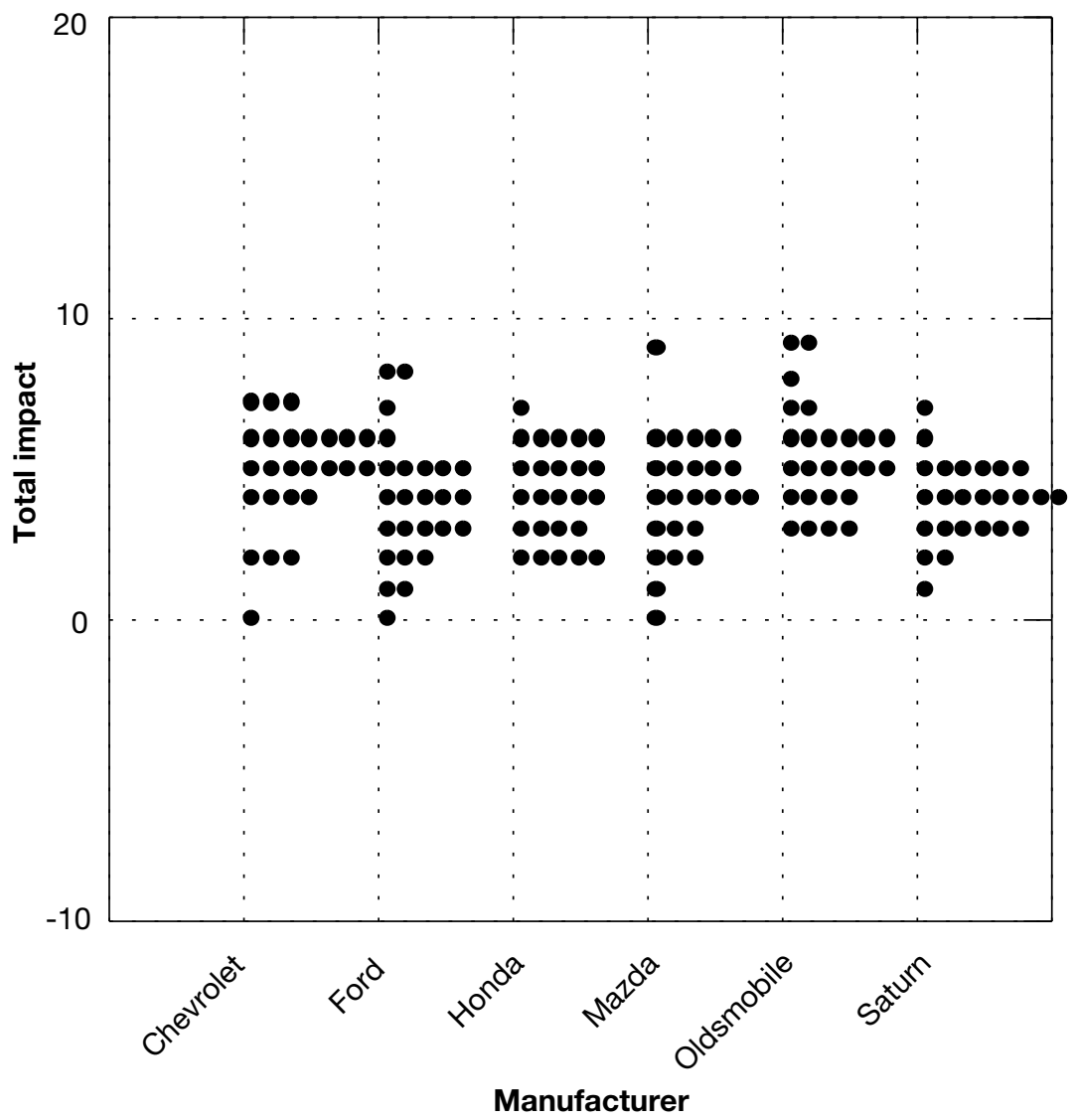

Figure 2: Density distribution of utility value by car model for the total panel (each circle is an element, the utility of the element is shown on the ordinate)

respectively, +0.88 versus those seeking information by the internet, +0.81 versus those seeking information through a friend's recommendation, and +0.63 versus those seeking information through car shows. The utility patterns across groups are fundamentally the same.

\section{Concept response segmentation}

The concept response segmentation of the sensory preference segmentation ${ }^{17}$ falls into the category of latent segmentation methods, which seek to uncover basic groups in the population that are not necessarily obvious from the conventional classification. The key difference between conventional latent segmentation and the approach used here comes from the fact that the segmentation used here applies the relation between utility value and semantic differential scale, as previously discussed.

The results from the segmentation reveal four clear clusters. These clusters can be most appropriately named by looking at the elements that do best. Table 7 shows the winning elements for each of the four segments.

Segment 4A (25 per cent of the respondents) is basically interested in the car (additive constant $=53$ ), but virtually nothing that one says about the car can increase the interest of this segment. It is unlikely that one can create a strong performing concept for this segment because nothing works. 
Table 6: Winning concept elements for three subgroups of respondents, who describe their interest in shopping for a car

\begin{tabular}{|c|c|c|c|c|c|}
\hline & & Total & Utility & Enthusiast & Non-shopper \\
\hline \multicolumn{2}{|c|}{ Additive constant } & 37 & 33 & 44 & 33 \\
\hline \multicolumn{6}{|c|}{ Self-described utilitarian } \\
\hline Ford & $\begin{array}{l}\text { An AM/FM stereo with single CD player } \\
\text { and premium sound }\end{array}$ & 8 & 10 & 5 & 7 \\
\hline Mazda & Traction control system & 9 & 10 & 6 & 10 \\
\hline Oldsmobile & Exhaust system made of stainless steel & 8 & 10 & 7 & 9 \\
\hline Ford & 15-inch eight-spoke aluminium wheels & 8 & 9 & 7 & 10 \\
\hline \multicolumn{6}{|c|}{ Self-described enthusiast } \\
\hline Oldsmobile & Rust and dent resistant steel body panels & 9 & 8 & 11 & 8 \\
\hline Oldsmobile & $\begin{array}{l}\text { Lock-out prevention feature }- \text { sounds a } \\
\text { chime and disables the power locks if } \\
\text { the ignition key remains in the ignition }\end{array}$ & 9 & 9 & 8 & 9 \\
\hline Oldsmobile & Exhaust system made of stainless steel & 8 & 10 & 7 & 9 \\
\hline Ford & 15-inch eight-spoke aluminium wheels & 8 & 9 & 7 & 10 \\
\hline \multicolumn{6}{|c|}{ Self-described non-shopper } \\
\hline Ford & 15-inch eight-spoke aluminium wheels & 8 & 9 & 7 & 10 \\
\hline Mazda & Traction control system & 9 & 10 & 6 & 10 \\
\hline Oldsmobile & $\begin{array}{l}\text { Lock-out prevention feature - sounds } \\
\text { a chime and disables the power locks } \\
\text { if the ignition key remains in the ignition }\end{array}$ & 9 & 9 & 8 & 9 \\
\hline Oldsmobile & Exhaust system made of stainless steel & 8 & 10 & 7 & 9 \\
\hline
\end{tabular}

Segment 4B (17 per cent of the respondents) likes safety and security features, especially simple, non-technical ones that connote family safety.

Segment 4C (29 per cent of the respondents) is far less interested in the car at a basic level (additive constant $=26$ ). However, this segment finds a large number of concept elements to be very interesting, with some elements showing utilities of 20 or higher. These elements are quite similar to each other. They present state-of-the-art technologies in an impressive form, allowing this segment to feel proud of the purchase because it is technologically up to date.

Segment 4D (29 per cent of the respondents) is also far less interested in the car at a basic level (additive constant $=23$ ). They like security and safety, combined with luxury. One can craft a very powerful message for these respondents. The current competition is doing this with a variety of messages that are exceptionally impactful, exhibiting utility values of 20 or higher.

The deconstruction of the different segments can be carried one step further in order to identify which particular communications, if any, clearly appeal to a specific segment. Most of the communications fail to appeal strongly to Segment 4B (family safe and secure, Figure 3). The communications do appeal to Segment 4C (demonstrable, state-of-the-art technology), and to Segment 4D (luxury facilitated, safety and security, Figure 4). There are at least three different hypotheses worth exploring:

- the internet-based interview missed a substantial number of Segment 4B respondents. If these respondents had participated, then perhaps their utility values would have been higher, but it is impossible to answer this question

- the deconstruction of material missed 
Table 7: Winning elements for the four concept response segments

\begin{tabular}{|c|c|c|c|c|c|c|}
\hline & & Total & $\begin{array}{l}\text { Segment } \\
4 A\end{array}$ & $\begin{array}{l}\text { Segment } \\
4 B\end{array}$ & $\begin{array}{l}\text { Segment } \\
4 C\end{array}$ & $\begin{array}{l}\text { Segment } \\
4 D\end{array}$ \\
\hline \multicolumn{2}{|c|}{ Base size of group } & 349 & 87 & 58 & 100 & 104 \\
\hline \multicolumn{2}{|c|}{ Additive constant } & 37 & 53 & 59 & 26 & 23 \\
\hline \multicolumn{7}{|c|}{ Segment 4A - Interested, non-responsive } \\
\hline Olds & $\begin{array}{l}\text { Safety cage construction: front and rear crush zones absorb } \\
\text { crash energy }\end{array}$ & 5 & 1 & -9 & 12 & 8 \\
\hline Saturn & Five-mph front and rear bumpers & 4 & 1 & -5 & 10 & 7 \\
\hline Honda & Linear steering helps eliminate unwanted steering effects & 3 & 1 & -8 & 8 & 6 \\
\hline Honda & 105,000 mile tune-up interval & 3 & 1 & -6 & 10 & 4 \\
\hline \multicolumn{7}{|c|}{ Segment 4B - Family safe and secure } \\
\hline Honda & An illuminated ignition switch & 7 & -2 & 9 & 15 & 7 \\
\hline Chevy & Comes with driver and front passenger air bags & 7 & -3 & 8 & 11 & 11 \\
\hline Olds & $\begin{array}{l}\text { Side impact protection: Steel door beams and interior padding } \\
\text { protect occupants in the event of a side impact }\end{array}$ & 6 & -3 & 8 & 12 & 7 \\
\hline Chevy & An electric rear-window defogger & 5 & -2 & 6 & 6 & 10 \\
\hline Mazda & Child safety seat anchors for rear seat & 5 & -3 & 6 & 12 & 3 \\
\hline Chevy & $\begin{array}{l}\text { Packaged with the right performance, convenience and } \\
\text { design features }\end{array}$ & 6 & -4 & 6 & 11 & 10 \\
\hline \multicolumn{7}{|c|}{ Segment $4 C$ - Demonstrable state-of-the-art 'technology' } \\
\hline Mazda & Traction control system & 9 & -2 & -4 & 22 & 12 \\
\hline Mazda & Roominess and comfort & 6 & -2 & -7 & 21 & 7 \\
\hline Ford & An AM/FM stereo with single CD player and premium sound & 8 & $-\overline{2}$ & -5 & 20 & 12 \\
\hline Honda & Comes with dual power mirrors & 6 & -3 & -4 & 19 & 8 \\
\hline Saturn & 2.2 litre, 4-cylinder engine & 7 & -4 & -4 & 19 & 11 \\
\hline Olds & Four wheel disc ABS brakes provide better stopping power & 6 & -1 & -9 & 18 & 11 \\
\hline Chevy & Comes with child security rear-door locks & 6 & -3 & -2 & 17 & 9 \\
\hline Chevy & Four-speed electronic automatic transmission with lock-up & 7 & 0 & -7 & 17 & 10 \\
\hline Chevy & Has 15 -inch full bolt-on wheel covers & 6 & -1 & -7 & 17 & 8 \\
\hline Saturn & Four-wheel independent suspension & 4 & -3 & -9 & 17 & 7 \\
\hline Chevy & Front disc/rear drum brakes with 4-wheel antilock braking system & 7 & -2 & -6 & 16 & 13 \\
\hline Chevy & Front independent strut suspension with anti-roll bar & 5 & -3 & -6 & 16 & 8 \\
\hline Olds & $\mathrm{V}-6200 \mathrm{lb}-\mathrm{ft}$ of torque generates good getaway & 6 & -2 & -7 & 16 & 9 \\
\hline Chevy & Brake/transmission shift interlock & 5 & -5 & -8 & 16 & 9 \\
\hline Ford & A $2.5 \mathrm{~L}$ six-cylinder engine $\mathrm{w} /$ four-speed automatic transaxle & 4 & -2 & -10 & 16 & 5 \\
\hline \multicolumn{7}{|c|}{ Segment 4D - Luxury facilitated safety and security } \\
\hline Mazda & $\begin{array}{l}\text { Comes with a Bose }{ }^{\circledR} A M / F M / c a s s e t t e / C D \text { stereo with four } \\
\text { speakers and digital clock }\end{array}$ & 5 & -7 & -10 & 6 & 21 \\
\hline Olds & $\begin{array}{l}\text { A rigid body structure comparable to some of Europe's finest } \\
\text { luxury cars }\end{array}$ & 5 & -5 & -6 & 6 & 20 \\
\hline Olds & Powerful all-disc braking system includes standard ABS & 5 & -7 & -6 & 5 & 20 \\
\hline Olds & Rust and dent resistant steel body panels & 9 & -2 & 1 & 13 & 19 \\
\hline Olds & Exhaust system made of stainless steel & 8 & -3 & -2 & 15 & 18 \\
\hline Olds & $\begin{array}{l}\text { Lock-out prevention feature sounds a chime and disables the } \\
\text { power locks if the ignition key remains in the ignition }\end{array}$ & 9 & -2 & 0 & 14 & 18 \\
\hline Saturn & Four-way hazard warning flashers & 4 & -6 & -8 & 6 & 18 \\
\hline Saturn & $\begin{array}{l}\text { Front suspension has independent gas-charged strut with } \\
\text { stabiliser bar }\end{array}$ & 3 & -7 & -9 & 4 & 18 \\
\hline Mazda & Comes with 16 -inch alloy wheels with locks and all-season radials & 4 & -5 & -7 & 3 & 18 \\
\hline Saturn & Five-speed manual transmission & 6 & -4 & -5 & 9 & 17 \\
\hline Ford & Will fit all interior needs & 4 & -7 & -9 & 8 & 17 \\
\hline Honda & New double-wishbone suspension system & 5 & -6 & -3 & 7 & 17 \\
\hline Saturn & Brake pads with audible wear indicators & 5 & -5 & -4 & 6 & 17 \\
\hline Ford & Built with side-door intrusion beams & 3 & -6 & -9 & 5 & 17 \\
\hline Mazda & Six-way power driver's seat & 3 & -7 & -8 & 4 & 17 \\
\hline
\end{tabular}




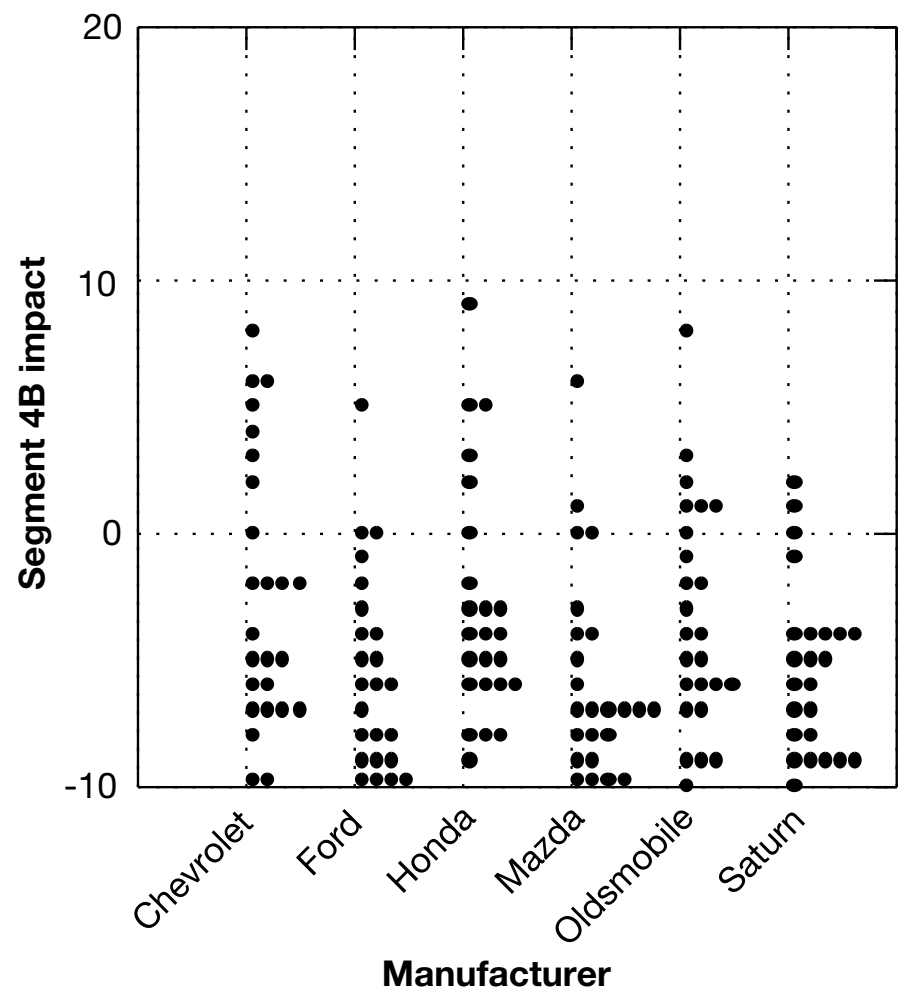

Figure 3: Utility values for Segment 4B (family safe and secure) arrayed by model providing the communication (each circle is a utility value)

the information relevant to Segment 4B. That is, quite possibly this segment would have reacted more to pictures (not included) or primarily to emotional statements (only a few included). This hypothesis is worth exploring. Perhaps the models whose communications are used in the deconstruction are not the appropriate ones

- the deconstruction was adequate and the representation of respondents was adequate. The truth of the matter is that this second segment is simply far less responsive to elements. This is closer to the probable truth because the highest utility for Segment 4B is only +9 .

Beyond the segmentations are the distributions of self-described attitudes and behaviour obtained from the classification questionnaire. The deconstruction and segmentation reveal dramatically different groups of consumers with mind-sets. However, the classification of these respondents into easy to find geodemographics is not straightforward. As Table 8 shows, these segments are intermingled in the population. Although there are some differences in geodemographics, the differences are minor compared to the differences in responsivity to elements. Age of respondent is the biggest geodemographic variable to show an effect of segmentation. One might expect that the attitudinal statements would differentiate the segments. These attitudinal statements do a somewhat better job than the geodemographics, but not dramatically so. One of the key differentiators is whether 


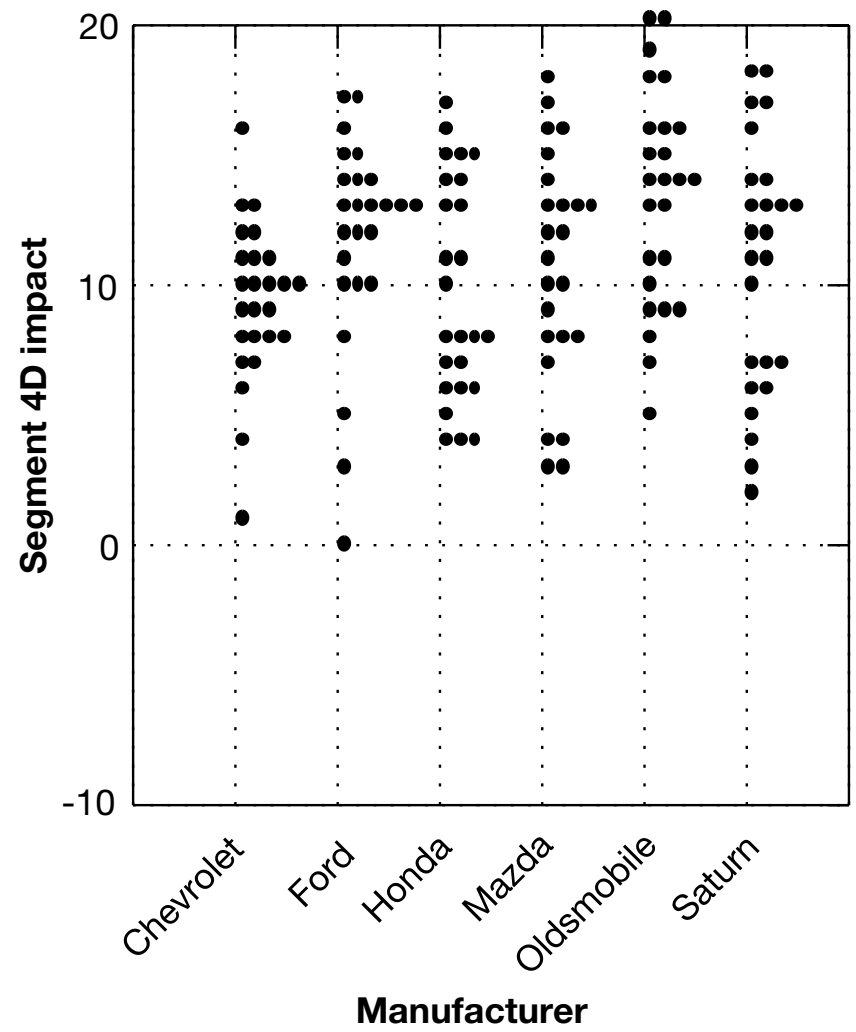

Figure 4: Utility values for Segment 4D (luxury facilitated, safety and security) arrayed by model providing the communication (each circle is a utility value)

or not respondents feel themselves to be utilitarian shoppers. More of the respondents feel themselves to be utilitarians than enthusiasts (48 to 42 per cent). This proportion reverses itself for Segment 4D (luxury facilitated safety and security). Surprisingly, the proportion holds for Segment 4C (state-of-the-art technology). One would have thought that these would be enthusiasts, but they are not.

\section{DISCUSSION}

\section{Uncovering brand strategies by their communications}

One of the benefits of deconstruction is a clearer understanding of the underlying brand strategy. The nature of the communications and the group most responsive to those communications are both indicators of what the strategy may be. The disciplined profiling of the in-market communications on a set of semantic profiles provides an in-depth look at the tonality of what is being communicated. Rather than relying upon the more conventional profiling of a brand or model name on a series of attributes, deconstruction relies upon a more extensive set of stimuli, and a less extensive set of rating attributes.

A comparison is worth making here. A conventional profiling exercise of brand names may use dozens of attributes. This extensive list of attributes is applied to the model name or brand name. The research focuses on what might be a relatively small list of such names - perhaps a dozen or two dozen. The stimulus set is thus 
Table 8: Classification of respondents into the four concept response segments

\begin{tabular}{|c|c|c|c|c|c|}
\hline & $\begin{array}{l}\text { Total } \\
\%\end{array}$ & $\begin{array}{l}\text { Segment } 4 A \\
\text { Interested, not } \\
\text { responsive } \\
\%\end{array}$ & $\begin{array}{l}\text { Segment } 4 B \\
\text { Family safe } \\
\text { and secure } \\
\%\end{array}$ & $\begin{array}{l}\text { Segment } 4 \mathrm{C} \\
\text { State-of-the-art } \\
\text { technology } \\
\%\end{array}$ & $\begin{array}{l}\text { Segment 4D } \\
\text { Luxury } \\
\text { facilitated } \\
\text { safety and } \\
\text { security } \\
\%\end{array}$ \\
\hline Total sample & 100 & 100 & 100 & 100 & 100 \\
\hline Males & 48 & 49 & 36 & 50 & 53 \\
\hline Females & 52 & 51 & 64 & 50 & 47 \\
\hline Age $21-35$ & 56 & 52 & 43 & 55 & 67 \\
\hline Age $36+$ & 44 & 48 & 57 & 45 & 33 \\
\hline Income up to $\$ 50 \mathrm{~K}$ & 47 & 53 & 36 & 48 & 47 \\
\hline Income $\$ 50 \mathrm{~K}+$ & 53 & 47 & 64 & 52 & 53 \\
\hline Primary sedan & 41 & 31 & 43 & 44 & 45 \\
\hline Primary SUV/minivan & 30 & 31 & 33 & 32 & 26 \\
\hline Buy within 12 months & 44 & 43 & 43 & 49 & 40 \\
\hline Buy within $12-18$ months & 44 & 49 & 41 & 41 & 44 \\
\hline Plan to buy sedan & 36 & 26 & 38 & 38 & 39 \\
\hline Plan to buy SUV/minivan & 54 & 59 & 43 & 55 & 56 \\
\hline Price $<\$ 20 \mathrm{~K}$ & 48 & 53 & 47 & 51 & 42 \\
\hline Price $\$ 20 \mathrm{~K}+$ & 52 & 47 & 53 & 49 & 58 \\
\hline Information from ads & 63 & 62 & 67 & 60 & 63 \\
\hline Information from web & 67 & 64 & 67 & 76 & 62 \\
\hline $\begin{array}{l}\text { Information from } \\
\text { recommendation }\end{array}$ & 48 & 45 & 40 & 54 & 50 \\
\hline Information from car shows & 34 & 37 & 31 & 39 & 27 \\
\hline Shop - utilitarian & 48 & 49 & 53 & 49 & 43 \\
\hline Shop - enthusiast & 42 & 41 & 36 & 41 & 48 \\
\hline
\end{tabular}

limited, but the array of responses is enormous. The researcher typically then works with an arsenal of data analysis tools in order to reduce the attribute rating list to a manageable set, and locates the limited set of brands or models on that reduced set. The result is a set of profiles and possibly a geometric representation.

The current approach stands in moderate opposition to this conventional approach. The current approach uses a wide array of communications provided by the different models. The information is in the test stimuli, not in the rating attributes. The stimuli are rated on a more manageable set of attributes (eg, six as was used here, but it could be as many as 12). The researcher can then look at the distribution of a single brand, in all its communications on the list of descriptor scales. The outcome reveals:
- what the brands communicate in their actual message

- whether the different communications of a single brand or model show a consistent direction, or whether the communication is unfocused. Lack of focus means either tonality of meaning (location on the semantic scale) or attractiveness to the target. A lack of focused attractiveness means that some messages communicate more for one group (eg male-oriented or expensive-oriented), and other messages communicate more for an opposing group (eg female-oriented or inexpensive-oriented). This is neither good nor bad, but just a measure of the degree to which the messages appeal to specific sub-groups

- the potential 'white space' or an attractive semantic profile that is not being occupied by an existing automobile model. 


\section{Latent segments in the population}

Although there are various methods for segmenting respondents, most marketers opt for the easy-to-find segments. The marketer's job is to prepare the market so that there is a demand for the product. It is critical for the marketer to identify individuals as belonging to a specific segment because once that identification is made the marketer can then target the individual with the right messages. It is quite easy to identify individuals with specific profiles, such as geodemographic groups, and then assume these to be homogeneous. To the degree that different geodemographic groups exhibit diverse preferences in communications, the marketing effort will be successful.

The deconstruction analysis indicates that there are at least four clearly defined segments in the population, and at least three segments that show strong reactions to different types of elements. The segments cannot be easily identified by their geodemographics. Yet, these clearly respond in different ways to the same messages. Furthermore, self-explicated attitudes do not work particularly well to create these radically different segments. Certainly there are some differences in response patterns from individuals who classify themselves in terms of shopping behaviour (utilitarian versus enthusiast), but whatever differences exist are minor. The same generally positive relationship exists among the different groups showing diverse ways of obtaining information about a car (from ads, from friends' recommendation, from car shows, etc).

The concept-response segments developed by relating utilities to semantic differential values may be more powerful because they create segments directly from the response of consumers to messages germane to automobiles. Rather than asking the respondent to classify himself or herself, the approach looks at the responses to the different messages, and then segments the respondents based upon those messages. In a sense the approach is far more behavioural (looking at respondents) and far more concrete (looking at specific elements dealing with the car itself).

\section{Jump-starting the creativity process}

The remarkably 'flat' performance of the concept elements for the total panel and the clear differences among elements for the segments suggests that it will be hard to improve these elements if the strategy involves either the total panel, or conventionally defined subgroups (self-stated attitudes or behaviours from the classification questionnaire). The total panel, generating a narrow range of element utilities and no negative elements, shows clearly that the material being communicated by the models has already been combed over in order to remove anything that could be a potential negative to the consumer. At the same time, the very low range of utilities means that either all of the respondents agree with each other about these modestly performing elements, or there exist segments in the population that disagree with each other. These segments counteract each other, so that, while one segment likes another segment it may be either actively disliked, or modestly disliked in return. The results are a low utility value for the total panel for the elements.

The high-scoring elements in the segments, which do not show up as strongly positive in the total panel, mean that the biggest opportunity for creativity exists with the segments. The deconstructed elements can be used as the source of the new material. It is important, however, that the creativity groups are set up to be relatively 
homogeneous. With homogeneous groups it is likely that the ideas of one respondent will spark new ideas in the mind of a like-minded individual. In contrast, creativity may not flow as well when the respondents in the creative session are of different minds. There may be new ideas flowing, but individuals in each group may have a mind-set that edits the elements subconsciously.

Respondents in a creative group tend to put forward ideas that they deem important and interesting. If the other individuals in the group belong to a different segment, then it is likely that these new ideas put forward may go nowhere because they need to spark creativity in individuals with a different mind-set. As a consequence the creativity step may be aborted, simply because of the differences in mind-sets.

\section{Identifying 'white space' in the competitive frame - some suggestions for possible next steps}

Deconstruction of the competitive frame also looks at where there are no elements for a particular product, and then creates a new product idea for that opportunity. ${ }^{18}$ The words 'white space' refer colloquially to areas that have not been taken advantage of. White space by definition is open and, therefore, no elements are there, or perhaps no complete concepts. Deconstruction data might, however, allow for some initial forays into filling that white space, if these five steps are followed:

- locate the elements on the semantic scale

- identify 'empty' areas in the semantic space. This identification may simply require a brute-force search through the geometric space, using some sort of simple enumeration algorithm. For example, one might divide each semantic scale into four discrete, non-overlapping segments (one to three, three to five, five to seven and seven to nine, respectively) and call these locations $\mathrm{Q}, \mathrm{R}, \mathrm{S}$ and $\mathrm{T}$, respectively.

- create a grid of all possible combinations. There are six semantic scale, of four segments each or $6^{4}$ combinations, this totals 46,656 combinations

- search through each of these grids by computer, determine whether there are elements in this space or in the surrounding, neighbouring space, and estimate how well the elements perform within the target segment

- a promising 'white space' corresponds to a location in the space that has few elements (little existing communication), but what exists in that location performs well with that segment.

\section{Methodology - Use of internet research and validation issues}

An ongoing issue in research is the utility and validity of internet-based interviews. Several years ago, when the internet was just achieving prominence, many meetings were devoted to issues of internet-based research. The Net Effects meetings, sponsored by ESOMAR (European Society of Market Research) debated the merits of such research. However, the increasing penetration of the internet in society, worldwide, and the ease of obtaining data means that the internet will not go away as a research venue. Comparative studies of internet and central location pre-recruit studies show that the data results are the same for conjoint measurement. ${ }^{19}$ There is still the problem of finding and incentivising the hard-to-find respondents, but this is a problem of research in general, rather than of the internet in particular. It is 
just that with the internet becoming so popular for research, old problems are now again rearing their heads.

One of the key aspects of conjoint analysis on the internet and, of course with deconstruction studies run by conjoint analysis, is the possibility of identifying consistent respondents versus inconsistent respondents. Validation now can become a measurement of respondent consistency in the model. The validity does not necessarily mean that people will do what they say they will do in an interview, but that is not a problem. The data in this study and in others, using the multiple $\mathrm{R}^{2}$ statistic, show that one can believe the vast majority of the data provided by an internet interview, even without an interviewer present to jot down the answers. This finding gives comfort to those who will use the internet for conjoint measurement research, and adds credence to the data obtained from deconstruction studies.

\section{References}

1 Porter, M. E. (1998) Competitive Advantage: Creating and Sustaining Superior Performance, Free Press, New York.

2 Luce, R. D. and Tukey, J. W. (1964)

'Simultaneous conjoint measurement: A new type of fundamental measurement', Journal of Mathematical Psychology, Vol. 1, pp. 1-27.

3 Wittink, D. R. and Cattin, P. (1989) 'Commercial use of conjoint analysis: An update', Journal of Marketing, Vol. 53, pp. 91-96.

4 Moskowitz, H. R. and Martin, J. G. (1993) 'How computer aided design and presentation of concepts speeds up the product development process', Proceedings of the 46th ESOMAR Conference, Copenhagen, Denmark, pp. 405-419.

5 Moskowitz, H. R., Itty, B., Shand, A. and Krieger, B. (2002) 'Understanding the consumer mind through a concept category appraisal: Toothpaste', Canadian Journal Of Market Research, Vol. 20, pp. 3-15.
6 Piccillo, S. (1999) 'How marketers benefit from mapping demos', Marketing News, Vol. 33, No. 12, pp. $15-16$.

7 Wells, W. D. (1975) 'Psychographics, A critical review', Journal of Marketing Research, Vol. 12, pp. 196-213.

8 Tittle, C. and Hill, R. (1967) 'Attitude measurement and prediction of behavior: An evaluation of conditions and measurement techniques', Sociometry, Vol. 30, No. 2, pp. 199-213.

9 Mitchell, A. (1983) The Nine American Lifestyles, MacMillan, New York.

10 Magidson J. and Vermunt, J. (2002) 'Latent class models', www.statisticalinnovations.com.

11 Green, P. E. and Krieger, A. M. (1991) 'Segmenting markets with conjoint analysis', Journal of Marketing, Vol. 55, pp. 20-31.

12 Moskowitz, H. R. (1996) 'Segmenting consumers worldwide: An application of multiple media conjoint methods', Proceedings of the 49th ESOMAR Congress, Istanbul, Turkey, pp. 535-552.

13 Moskowitz, H. R. (1996) 'Segmenting consumers on the basis of their response to concept elements: An approach derived from product research', Canadian Journal of Market Research, Vol. 15 , pp. $38-54$.

14 Moskowitz, H. R., Cohen, D., Krieger, B. and Rabino, S. (2001) 'Interest and reaction time analysis to credit card offers: Managerial implications of high level research procedures', Journal of Financial Services Marketing, Vol. 6, pp. 172-189.

15 Moskowitz, H. R. and Itty, B. (2002) 'Identifying consumer needs for functional foods from analysis of current communications on the Internet', Appetite, in review.

16 Moskowitz and Martin (1993) op. cit.

17 Moskowitz, H. R., Jacobs, B. E. and Lazar, N. (1985) 'Product response segmentation and the analysis of individual differences in liking', Journal of Food Quality, Vol. 8, pp. 168-191.

18 Newell, S. M. (2001) 'Distortion of "Fast Clockspeed" Product Development: Using Web-based Conjoint Analysis, Clockspeed Analysis and Technology Strategy for an Automotive Telematics System', thesis, MIT, MIT Press, Cambridge, MA.

19 Moskowitz, H. R., Gofman, A., Tungaturthy, P. Manchaiah, M. and Cohen, D. (2000) 'Research, politics and the Internet can mix: Considerations, experiences, trials, tribulations in adapting conjoint measurement to optimizing a political platform as if it were a consumer product', Proceedings of Net Effects, conference held in Dublin, 10-12th April, ESOMAR, pp. 109-130. 